\title{
Letter to the Editor: Would the Frequent Surveys Over the Year Be Necessary to Assess the Falls and Falls Related Problems Appropriately and Accurately in Community- Dwelling Older Adults?
}

I have read the article by Yoo et al. ${ }^{1)}$ with great interest. I appreciate the effort involved in this study to evaluate the discrepancy between quarterly recall and annual recall of falls in surveys involving older adults. The research related to this issue is a timely and necessary trial because most previous surveys have not adequately considered the potential for recall bias in the self-reported data. Particularly, older adults may be more likely to report their experience differently depending on the frequency or interval of the survey. ${ }^{2)} \mathrm{Al}-$ though this study covered a common topic, there have been few studies to support the evidence related to this issue.

Generally, I agree with the conclusion that quarterly surveys over a year are superior to annual surveys for older adults because they can recall the number of falls they experienced more accurately in the former situation. However, there is an issue of possible bias related to the nature of questions used in the survey. The participants were asked whether they had experienced any falls over the 3 months and simultaneously asked to recall the total number of falls over the last 1 year during the fourth quarterly survey. I wonder how many individuals reported discrepancies in the number of falls between quarterly and annual recalls among the 19 subjects who newly experienced falls within the preceding 3 months of the fourth survey. They may not have remembered their fall experiences before the last survey, and

\footnotetext{
Kyoung Ho Seo

Department of Rehabilitation Medicine, Hallym University Dongtan Sacred Heart Hospital, Hwaseong, Korea
}

Corresponding Author: Kyoung Ho Seo

Department of Rehabilitation Medicine, Hallym University Dongtan Sacred Heart Hospital, 7 Keunjaebong-gil, Hwaseong 18450, Korea

Tel: +82-31-8086-2350, Fax: +82-31-8086-2317

E-mail: caupmr@hallym.or.kr

Received: February 28, 2018

Revised: February 28, 2018

Accepted: March 8, 2018 so could have considered their fall experiences during the fourth quarter as the fall events for 1 year. Therefore, the difference in recall between quarterly surveys and annual surveys may not be compared properly when 3-month recalls and 1-year recalls are asked simultaneously. This may be one of the reasons for the increased recall discrepancy among the fallers who experienced more than one fall compared to those who fell only once per year. If the subjects' memory decay is a major problem as described in the discussion, the use of additional tools such as self-reported calendars, ${ }^{3)}$ patient diaries, ${ }^{4)}$ postcards, ${ }^{5}$ ) etc. would be helpful in assessing the fall events. One study reported that a self-reported monthly falls calendar is superior to quarterly telephone recalls in the tracking of the falls. ${ }^{6}$ Additionally, it would be more informative if this study suggests reasons for the differences in clinical characteristics between the 29 identical recalls and 29 discrepant recalls of the number of falls.

Also, what is the most appropriate frequency or interval of surveys to assess falls and fall-related problems among community-dwelling older adults? Of course, the more frequent surveys or interviews, for example, monthly or 3-monthly, must have an advantage of assessing those problems more accurately. Instead, the more frequent surveys result in an increased burden on manpower and economic costs. In a sense, it is necessary to evaluate whether the 6-month surveys are appropriate by comparing them with quarterly and yearly surveys.

Despite the limitations of this study, I think it is a meaningful study. Further studies are needed to identify more appropriate intervals or frequencies of surveys.

Conflicts of Interest Disclosures: The researcher claims no conflicts of interest.

\section{REFERENCES}

1. Yoo J, Kim S, Park WC, Kim BS, Choi H, Won CW. Discrepancy between quarterly recall and annual recall of falls: a survey of older adults. Ann Geriatr Med Res 2017;21:174-81.

2. Hunger M, Schwarzkopf L, Heier M, Peters A, Holle R; KORA

Copyright (C) 2018 by The Korean Geriatric Society

This is an open access article distributed under the terms of the Creative Commons Attribution Non-Commercial License (http://creativecommons.org/licenses/by-nc/4.0/) which permits unrestricted non-commercial use, distribution, and reproduction in any medium, provided the original work is properly cited. 
Study Group. Official statistics and claims data records indicate non-response and recall bias within survey-based estimates of health care utilization in the older population. BMC Health Serv Res 2013;3:1. https://doi.org/10.1186/1472-6963-13-1.

3. Tromp AM, Pluijm SM, Smit JH, Deeg DJ, Bouter LM, Lips P. Fall-risk screening test: a prospective study on predictors for falls in community-dwelling elderly. J Clin Epidemiol 2001;54: 837-44.

4. Hill AM, Hoffmann T, Haines TP. Circumstances of falls and fallsrelated injuries in a cohort of older patients following hospital discharge. Clinical Interv Aging 2013;8:765-74.

5. Dawson-Hughes B, Harris SS, Krall EA, Dallal GE. Effect of calcium and vitamin D supplementation on bone density in men and women 65 years of age or older. N Engl J Med 1997;337: 670-6.

6. Hannan MT, Gagnon MM, Aneja J, Jones RN, Cupples LA, Lipsitz LA, et al. Optimizing the tracking of falls in studies of older participants: comparison of quarterly telephone recall with monthly falls calendars in the MOBILIZE Boston Study. Am J Epidemiol 2010;171:1031-6. 